\title{
Bridging Gaps in College Students' Source Perception and Use
}

\author{
대학생들의 정보원에 대한 인식과 이용간의 차이에 대한 분석연구
}

\author{
Kyung-Sun Kim (김경선)* \\ EunYoung Yoo-Lee (유이은영)** \\ Nahyun Kwon (권나현)***
}

\begin{abstract}
The study examines two aspects that relate to undergraduates' selection and use of information sources for their academic assignments: (1) sources perceived useful vs. sources frequently used, and (2) source characteristics considered important as selection criteria vs. selection criteria used as reflected in characteristics of frequently used sources. A survey of 251 undergraduate students attempted to address the gaps between what students think they should do and what they actually do with regard to source selection. Characteristics of frequently used sources were analyzed to find out the criteria used for source selection. Friends/family were among the frequently used sources although they were not perceived as useful. Unlike other sources suffering gaps between the perceived usefulness and the use behavior, Web sources were the ones not only perceived most useful but also used most frequently. When the important selection criteria were compared with the characteristic of sources used often, students did not seem to actually use the selection criteria they thought important. While students considered some characteristics related to information quality (e.g., accuracy, comprehensiveness) as important criteria for source selection, the actual criteria they applied for choosing information sources could be described as 'convenient' or 'accessible' (e.g., efficient/time saving, easy to use, familiar, accessible). Based on the findings, suggestions were made to help bridge such gaps through information literacy programs and information systems design.
\end{abstract}

\section{초 록}

본 연구는 대학생들의 학업과제수행에 필요한 정보원에 대한 인식 및 선택과 그 이용과 관련하여, 학생들이 (1) 유용하다고 인식하는 정보원과 자주 이용하는 정보원의 차이를 비교하고, (2) 정보원 선택 시 중요하게 생각하는 정보원의 특성과 자주 이용하는 정보원의 특성을 비교, 분석함으로써, 학생들의 정보원에 대한 인식과 실제 이용행동간의 차이를 파악하고자 하는 목적으로 수행되었다. 미국 대학생 총 251 명을 대상으로 설문조사를 실시한 연구결과에 따르면, 학생들이 가장 빈번히 이용하는 정보원이자 가장 유용한 정보원은 웹자원으로 밝혀졌다. 온라인 $\mathrm{DB} /$ 저널은 가장 빈번히 사용된 정보원은 아니었지만 유용한 정보원으로는 인식되고 있었다. 또한 '정확성'이나 '망라성' 등과 같은 정보의 품질을 정보원 선택의 중요한 기준으로 생각은 하지만 실제로는 편리하고 접근가능한 정보원을 선택하고 있음이 밝혀졌는데, 이는 대학생들이 중요하다고 생각하는 선택기준에 근거해 정보원을 선택하지 않고 있음을 보여준다. 정보원의 선택기준과 실제 이용간의 간극을 보여주는 이러한 연구결과를 토대로 대학생들이 양질의 정보원을 선택하도록 도울 수 있는 정보활용교육과 더 사용하기 쉽고 편리한 정보시스템 설계를 위한 방안을 제시하였다.

Keywords: information use, source selection, college students, information literacy, selection criteria, source perception

정보이용, 정보원선택, 정보품질, 대학생, 정보활용교육

* Associate Professor, School of Library and Information Studies, University of Wisconsin-Madison (kskim@slis.wisc.edu)

** Associate Professor, School of Library and Information Sciences, North Carolina Central University (eunyoung@nccu.edu)

*** Professor, Department of Library \& Information Science, Myongii University (nahyun.kwon@gmail.com) (Corresponding author)

- 논문접수일자 : 2013년 5월 20일 - 최초심사일자 : 2013년 6월 9일 - 게재확정일자 : 2013년 9월 6일

- 정보관리학회지, 30(3), 7-21, 2013. [http://dx.doi.org/10.3743/KOSIM.2013.30.3.007〕 


\section{Introduction}

In this digital age, undergraduate students can access a wide range of information sources through various channels. Such an abundance of sources has made the evaluation and selection of quality sources particularly crucial. For academic librarians, especially those in charge of information literacy education, teaching college students how to choose reliable sources has become an increasingly important and complex endeavor.

Most of today's undergraduates have grown up as active users of various information tools and sources made available through the Internet. While confident about their knowledge and skills in using information sources, they tend to have very little understanding of the availability, function and purpose of library resources (Gardner \& Eng, 2005; Holiday $\& \mathrm{Li}, 2004)$. Information literacy (IL) education has been a major concern among educators and librarians as it helps students find, evaluate and use information effectively and efficiently (Rockman, 2004).

The study examines two aspects related to the selection and use of information sources in academic contexts: (1) sources perceived useful vs. sources frequently used, and (2) source characteristics considered important as selection criteria vs. characteristics of frequently used sources. Until now, few studies have empirically investigated possible gaps in college students' source perception and actual use. Thus, this study aims to help understand source attributes that lead students to use certain sources over others, by addressing gaps between what students think they should do and what they actually do regarding source selection. Based on the findings, suggestions are made to refine $\mathrm{IL}$ programs and information systems design to support students choose quality sources.

\section{Literature Review}

\subsection{Source Use by Undergraduates}

Over the past decade, researchers have paid more attention to the selection of information sources to capture any changes in selection and use of sources. Source selection by youths including college students is of particular interest as it can help to identify problems they encounter and also to develop IL programs to improve their source evaluation skills.

Currently, typical undergraduates are from the Generation Y or the Millennial Generation, who were born between the early 1980s and 2000s (Generation Y, p. 16.d). Those in the Generation Y, a term first known to be appeared in Ad Age (Generation Y, p. 16.d) are often characterized as heavy users of the Web. They are also known to have little knowledge about information sources and lack search skills (Holliday \& Li, 2004). Researchers consistently report that these undergraduates prefer electronic resources, especially Web-based resources; and that they cannot evaluate the quality of sources properly. In a study analyzing works cited in undergraduates' term papers, Davis (2003) found a significant increase in the number of non-scholarly sources cited, including Web resources, while book citations suffered 
a significant decrease. Observing undergraduates' research habits in an academic library, Van Scoyoc and Carson (2010) also found that Web resources were the most commonly used source: about $76 \%$ of the undergraduates used Web sources. The popularity of Web sources among college students was also well documented in other studies that examined in academic and non-academic uses conducted in different countries (Kim \& Sin, 2005; Head \& Eisenberg, 2009; Lee, 2010; Yoon, 2004).

Some researchers attempted to find out why undergraduate students rely heavily on the Web despite its varying quality. Two common issues were identified. First, students tend to be unaware of various information sources available to them. Second, they are more likely to pursue instantly available sources that involve minimal effort. The popularity of Wikipedia among undergraduate students is a precise example of such a tendency (Lim, 2009; Head \& Eisenberg, 2010a). Interviewing undergraduates, Lee (2008) discovered that most students considered the Web as the first source to consult for their course work. Her study also suggested that the role library resources play in meeting students' information needs has decreased because students often rely on the Web to provide "instant availability and convenience" (p. 215). In a longitudinal study of undergraduates in the United Kingdom, Warwick and her colleagues described how students use different information sources for their academic assignments (Warwick, Rimmer, Blandford, Gow, \& Buchanan, 2009). Similar to other extant studies, their research revealed that students tended to avoid print-based sources in favor of Web-based sources. It also found that students repeated the same search strategies, even unsuccessful ones, relying on keyword searches. The most astounding was that instead of becoming better at using and refining search strategies, the undergraduates became experts at finding the most efficient way to finish their research tasks. They learned searching methods that resulted in the quickest and easiest retrieval of just enough information necessary to complete the task at hand. The researchers refer to this as "strategic satisficing" (p. 2409). This phenomenon can also be explained by the principle of least effort where information searchers choose to use known or familiar sources in order to reduce uncertainty and complexity in the information seeking situation (Kuhlthau, Heinström, \& Todd, 2008; Mann, 1987; Valentine, 1993).

\subsection{Criteria for Selecting Information Sources}

When individuals choose certain information sources over others, do they have any particular criteria they value and apply? Some studies examined the criteria that users prefer to use and also obstacles they encounter when selecting information sources. In a focus group study with college students and faculty, Young and Von Seggern (2001) investigated what criteria users employed in selecting information sources. Although the Web was reported as the most frequently used source due to its availability and ease of use, users viewed other criteria including reliability, accuracy and cost to be important as well. 
When asked about obstacles to finding quality sources, participants mentioned information overload (or infoglut) and time consistently.

Burton and Chadwick (2000) surveyed college students to identify the students' preferred criteria when evaluating Internet-based and library-based sources. Their study found that students generally ranked highly the easy-to-use and easy-to-find sources, and that the criteria for evaluating sources were very similar regardless of source types (i.e., library-based vs. Internet-based sources). This study examined source selection criteria in the group level (i.e., Internet sources vs. library sources), not in the individual source level (e.g., books, journals, etc.). A close examination on individual information sources could help understand students' source perception more accurately. More recently, Header and Eisenberg (2010b) also studied college students' information evaluation behavior. They found that students used a higher number of criteria when evaluating Web sources than library sources. In this study, however, the selection criteria that students reported to use were not compared against the criteria that students consider important. In a survey of undergraduate students, Kim and Sin (2007) investigated source perception and evaluation, and how these were affected by students' problem-solving styles. In general, students considered "accuracy / trustworthiness" as the most important criteria for selecting sources, but the sources they used most frequently were not the ones viewed as accurate. It was also found that the source selection was influenced by users' problemsolving styles.

\section{Method}

\subsection{Research Questions}

The study focuses on two aspects related to source selection and use: (1) What are the sources that undergraduates perceive to be useful for their academic assignments? Are they different from the sources undergraduates use frequently?, and (2) What are the source characteristics that undergraduates consider important as selection criteria? Are they different from the criteria actually used as reflected in the characteristics of sources that undergraduates frequently use?

The first question focuses on the gap between the sources that undergraduate students think they should use and the sources that they actually use. The second question helps reveal any discrepancies between the source characteristics that undergraduates think they should use as selection criteria and the characteristics of sources they use frequently. Both questions will help reveal whether any relationship exists between what students think and what they actually do when selecting sources. The findings will shed light on undergraduates' source selection behavior.

\subsection{Data Collection}

Data were collected at a public university in the southern part of the United States, using a self-administered survey. The survey questionnaire included questions about the participants' demographic char- 
acteristics and their perception and use of information sources for their academic assignments. The information sources examined in this study include Website/search engines, online databases/journals, print journals, print books, print dictionaries, friends/ family, OPAC, and librarians. Students' perception of source characteristics was measured using semantic differential ratings scale, developed based on a well-established theory (Osgood, Suci, \& Tannenbaum, 1957; Osgood, 1962). Under each information source, a list of adjectives was presented with "polar" opposites (e.g., accurate vs. inaccurate). Two adjectives of each pair were separated by a seven-step scale, and participants were asked to rate based on their perception of the information source. On the final version of the survey, eight different types of sources were rated on thirteen sets of source characteristics.

Sources and their characteristics included in the questionnaire were determined based on the related literature and results from two pilot studies with undergraduate and graduate students (Kim \& Sin, 2007). In preparation of the semantic differential ratings scale, over a hundred of students were asked to list all the characteristics that they could associate with various sources. The data collected were analyzed and grouped using factor analysis, which resulted in thirteen pairs of characteristics. The identified source characteristics used in the study include: accessible-inaccessible, accurate-inaccurate, active-passive, comprehensive-incomprehensive, easy to use-difficult to use, efficient/time saving - inefficient, familiar-unfamiliar, free-costly, good-bad, interesting-uninteresting, objective-subjective, or- ganized-unorganized, and strong-weak. Among the characteristics, "good-bad", "strong-weak", and "active-passive" were included as references that can be used to verify the grouping of the evaluation, potency and activity related characteristics, respectively (Himmelfarb, 1993). Participants were recruited on a voluntary basis by soliciting emails via the campus Intranet and posting flyers on campus. Participants received a bookstore gift card as an incentive for their participation.

\subsection{Participants}

Two hundred and fifty-one undergraduate students participated in the study. The sample distribution by gender showed that $61 \%$ of the participants were female and $39 \%$ male. This is similar to the university-wide student profile: about $67 \%$ of the student population was female and $33 \%$ male. In terms of their age, $77 \%$ of the participants were between 18 and 22 , and $11 \%$ between 23 and 29 years old. They were from all different levels: freshmen (31\%), sophomore (24\%), junior (22.5\%), and senior (22.5\%). Regarding their academic background, most of the participants were from the social sciences (55\%), followed by science and engineering (24.3\%), humanities (4.5\%), and undecided. Over $98 \%$ of the participants $(n=247)$ were full-time students and over $53 \%(n=131)$ were currently employed.

As a non-probability sampling method was used, the sample used in the study may not be representative of the undergraduate population. Thus, generalization of the study findings should be made with caution. 


\section{Findings}

\subsection{Sources to Use vs. Sources Used}

To find out what sources the undergraduates viewed useful for their academic assignments, participants were asked to rank sources based on their perceived usefulness among the eight sources, namely Website/search engines, online databases/journals, print journals, print books, print dictionaries, friends/ family, OPAC, and librarians. The result showed the top five sources as: (1) Websites and search engines, (2) online databases/journals, (3) books, (4) dictionaries, and (5) journals. To find out what sources undergraduates actually use for their academic work, participants were asked how often they used different sources for their assignments. The five most frequently used sources included: (1) Websites and search engines, (2) books, (3) friends/family, (4) online databases/journals, and (5) dictionaries (See Table 1).

Web sources were used most frequently as reported in previous studies (Scoyoc \& Cason, 2010). They were used almost daily. Interestingly, Web sources were also perceived to be most useful among the eight sources. Books and friends/family were also fairly often used sources. It is worthwhile to note that among the "people" sources, friends/family were one of the most frequently used sources whereas librarians were the least used source. However, students perceived neither of the "people" sources useful.

In order to find out the gaps between the sources students viewed useful and the sources they frequently used more clearly, we employed the graphical representation of the gap as shown in Figure 1. Notable among the gaps identified is the gap found in friends/family. Friends/family was not among the top five sources considered useful, but ranked as the third most used one. While most of the sources suffer such gaps, Web sources were consistently the top in both the perceived usefulness and the frequency of use.

$\langle$ Table 1〉 Sources perceived useful vs. Frequently used sources

\begin{tabular}{c|l|c|l|c}
\hline & \multicolumn{2}{|c|}{ Sources Perceived Useful } & \multicolumn{2}{c}{ Sources Used Frequently } \\
\hline Rank & \multicolumn{1}{|c|}{ Sources } & Mean $^{1}$ & \multicolumn{1}{|c}{ Sources } & Mean $^{2}$ \\
\hline 1 & Website/search engines & 3.74 & Website/search engines & 5.43 \\
2 & Online databases/ & 2.50 & Books & 4.32 \\
& journals & & & 4.04 \\
3 & Books & 2.47 & Friends/ Family & 4.02 \\
4 & Dictionaries & 1.77 & Online databases/ & 3.79 \\
& & & journals & Dictionaries \\
\hline
\end{tabular}

1. Not useful (0); most useful (5)

2. Not used (0); used yearly or less (1); used twice or more a year (2); used monthly (3); used twice or more a month (4); used weekly (5); used daily (6) 


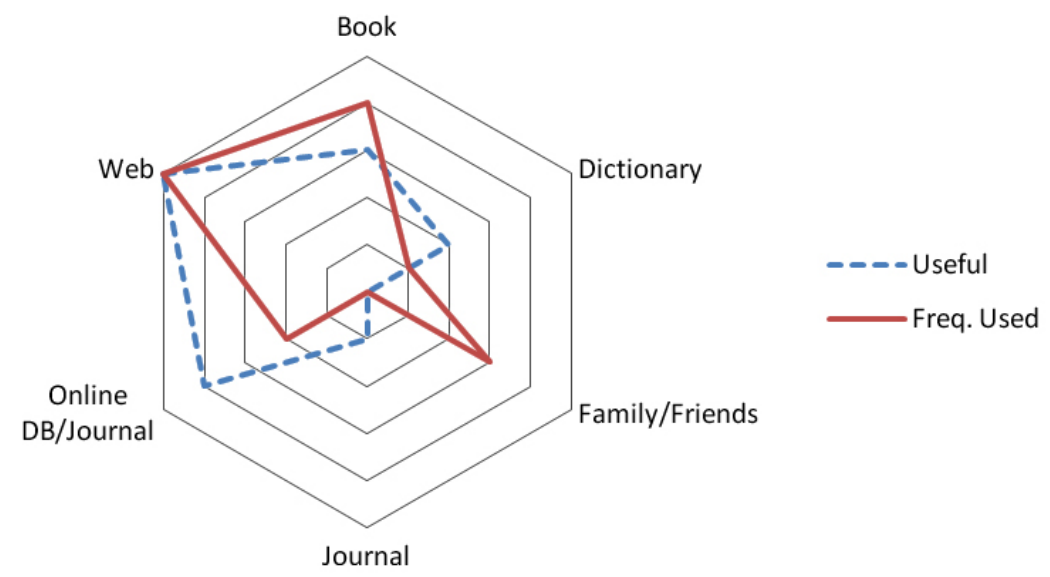

〈Figure 1〉 Gaps between perceived usefulness and frequency of use

\subsection{Selection Criteria Considered Important vs. Selection Criteria Used}

The second research question was: What are the source characteristics that undergraduates consider important as selection criteria? Are they different from the criteria actually used as reflected in the characteristics of sources that undergraduates frequently use?

Participants were asked to rank the source characteristics that they considered important for selecting sources. As Table 2 shows, the five most important criteria were: (1) accurate, (2) accessible, (3) easy to use, (4) free, and (5) comprehensive. Next, in order to find out whether participants actually selected sources based on such important criteria, the characteristics of the frequently used sources were examined using the semantic differential rating scores. For this, only the sources used at least weekly were selected and their scores were used in the analysis. As a result, characteristics of frequently used sources were best described by the following: (1) easy to use, (2) familiar, (3) accessible, (4) efficient/time saving, and (5) interesting (Table 2).

〈Table 2〉 Important criteria for source selection vs. Characteristics of frequently used sources

\begin{tabular}{c|c|c}
\hline Rank & $\begin{array}{c}\text { Important Characteristics to Use } \\
\text { as Selection Criteria }\end{array}$ & $\begin{array}{c}\text { Characteristics of Frequently } \\
\text { Used Sources }\end{array}$ \\
\hline 1 & Accurate & Easy to use \\
2 & Accessible & Familiar \\
3 & Easy to use & Accessible \\
4 & Free & Efficient/Time saving \\
5 & Comprehensive & Interesting \\
\hline
\end{tabular}


A further analysis was conducted to find out whether participants actually applied the selection criteria they considered as important when selecting sources. Using Spearman's rank correlation, two sets of 10 ranked characteristics were compared: ranks of those considered as important selection criteria, and ranks of those characterizing frequently used sources. The resulted Spearman's correlation coefficient was not significant $(\rho=0.348, p=0.324)$. That is, when selecting sources, participants did not necessarily apply the selection criteria that they claimed to be important.

This finding suggests that a gap exists between the criteria that undergraduates consider important for source selection and the criteria they actually use when selecting sources. Although there is some overlap between the two lists - "accessible" and "easy to use" - the results revealed that students did not necessarily use the selection criteria they thought important when actually selecting sources. While students seemed to consider some characteristics related to information quality (e.g., accuracy, compre- hensiveness) as important criteria for source selection, the information sources they selected could be described as "convenient" or "accessible" (e.g., efficient/time saving, easy to use, familiar, accessible). Undergraduates seem to willingly compromise the 'quality' for the sake of 'convenience' (Warchick, Rimmer, Blandford, Gow, \& Buchanan, 2009; Young \& Von Seggern, 2001).

\subsection{Online Sources: Characteristics Related to the Frequent Use}

An additional analysis was conducted to learn how the undergraduates viewed two online resources (i.e., Web sources \& online databases/journals). As presented in Table 3, there existed conspicuous differences between the two sources. Surprisingly, Web sources were perceived as superior to the online databases in all aspects, even in the "accuracy" attribute. The other interesting finding is that the profile of Web source characteristics seemed to be almost the

〈Table 3〉 Perceived characteristics of the Web sources and online databases/journals

\begin{tabular}{c|l|c|l|c}
\hline & \multicolumn{2}{|c|}{ Websites/Search engines } & \multicolumn{2}{c}{ Online DBs/Journals } \\
\hline Rank & Characteristics & Mean* & Characteristics & Mean* \\
\hline 1 & Free & 6.62 & Free & 5.78 \\
2 & Accessible & 6.56 & Comprehensive & 5.53 \\
3 & Easy to use & 6.56 & Accurate/Trustworthy & 5.52 \\
4 & Familiar & 6.56 & Organized & 5.52 \\
5 & Interesting & 6.49 & Accessible & 5.49 \\
6 & Comprehensive & 6.36 & Objective & 5.46 \\
7 & Efficient & 6.36 & Efficient & 5.45 \\
8 & Organized & 6.34 & Interesting & 5.42 \\
9 & Accurate/Trustworthy & 6.21 & Easy to use & 5.38 \\
10 & Objective & 6.17 & Familiar & 5.33 \\
\hline
\end{tabular}

* Based on semantic differential rating scores: Extremely agree (7); Extremely disagree (1) 
opposite of the online databases. That is, three of the top five characteristics describing the Web sources - easy-to-use, familiar and interesting - were found among the bottom three characteristics describing the online databases(DB)/journals.

As the findings indicated that the undergraduates tend to perceive easy-to-use sources, such as the Web, useful and also to use them often, we were interested in finding out whether such tendencies would remain unchanged as students advance to upper level classes. The simple linear regression analysis revealed a significant relationship between academic class level and the perceived usefulness of online DBs/journals $(\mathrm{r}=.31, p<.01)$. That is, students in upper level classes were more likely to perceive online DBs/journals as useful. Obviously, students have learned that online $\mathrm{DBs} /$ journals are useful for their academic work as they gain more experience at college. Although such a positive relationship was not significant in the frequency of using online DBs/journals $(\mathrm{r}=.11, p=.22)$, the results showed an interesting pattern that might be related to the effect of information literacy instruction. The frequency of using DBs that was measured on a seven-point scale (Table 1) where " 0 " being "Not used" and " 6 " being "used daily" was examined by academic class level, the mean frequency of DB use constantly increased from sophomore through senior years (e.g., freshman (4.11), sophomore (3.63), junior (3.82), and senior (4.58)). Note that the numbers in the scale indicate as follows: "3" being "used monthly," "4" being "used twice or more a month," and " 5 " being "used weekly." Interestingly, however, the freshman class was found to use DB more often than sophomore and junior. The high level of DB use by freshmen might be a temporary effect of the mandatory IL instruction at the University the participants were affiliated. The mandatory IL instruction was offered to all freshmen via a course-related instruction before the data collection. The increased DB use in upper class years may be attributed to the fact that American college students build more experience with various databases as they advance to the upper class levels in college. At the same time, students also seem to struggle with using the DB sources as reflected in the rather lower level of usage compared to others such as the Web sources, print books, and friends/family. This might be due to the perceived difficulty in using online DBs.

\subsection{Human Sources: Characteristics of Friends/Family vs. Librarians}

Another additional analysis was conducted with respect to two human sources, namely friends/family vs. librarians. When we compared how the undergraduates viewed the two human sources, it revealed obvious differences between the two as shown in Table 4. First, friends/family was viewed far more positively than librarians in all dimensions. That is, friend/family received over 5.5 points in all ten dimensions of source characteristics, while librarians were scored as such in only two dimensions. Second, when top five characteristics of the two sources were compared, friend/family was viewed as more familiar and interesting than librarians. It should be noted 
$\langle$ Table 4〉 Perceived characteristics of friends/family and librarians

\begin{tabular}{c|l|c|l|c}
\hline & \multicolumn{2}{|c|}{ Friends/Family } & \multicolumn{2}{c}{ Librarians } \\
\hline Rank & Characteristics & Mean* & Characteristics & Mean* \\
\hline 1 & Free & 6.12 & Free & 5.79 \\
2 & Familiar & 5.98 & Accessible & 5.53 \\
3 & Interesting & 5.94 & Organized & 5.29 \\
4 & Accessible & 5.88 & Easy to use & 5.20 \\
5 & Easy to use & 5.83 & Efficient & 5.18 \\
6 & Efficient & 5.79 & Accurate/Trustworthy & 5.18 \\
7 & Comprehensive & 5.66 & Familiar & 5.13 \\
8 & Objective & 5.59 & Comprehensive & 5.08 \\
9 & Organized & 5.52 & Objective & 5.07 \\
10 & Accurate/Trustworthy & 5.51 & Interesting & 4.99 \\
\hline
\end{tabular}

* Based on semantic differential rating scores: Extremely agree (7); Extremely disagree (1)

that friends/family was the third most frequently used source (See Table 1), whereas librarians was found to be the least frequently used one. Similar to the findings on online sources, participants seem to prefer using sources that are familiar and interesting.

\section{Discussion \& Implications}

In this study, Web sources were perceived to be superior to others, and ranked as the most useful and the most frequently used source. This might be mainly due to students' positive experience and familiarity with the Web. The five strongest characteristics of Web sources perceived by students were free, familiar, accessible, easy to use, and interesting. Students perceived Web sources as easily accessible in various aspects - economically (e.g., free), psychologically (e.g., easy to use, familiar), physically (e.g., accessible) - while it offers something interesting without requiring much effort from themselves. Despite users' positive experience with the Web, the findings raise some concerns about their source perceptions. Participants perceived the Web sources far much positively than any other sources, even in the areas of 'accurate,' 'objective,' and 'organized,' despite the often inaccurate and poor quality of information found on the Web. This reflects some misperception that needs to be adjusted. In addition, students seemed to feel that it was not too risky to use the information from the Web. Research shows that people tend to be less sensitive to uncertain outcomes as long as they do not have to take risks (Tversky \& Fox, 2000). It confirms the findings from other studies (Gerstberger \& Allen, 1968; Zipf, 1949, p. 1): users act not to maximize gain, but to minimize loss; and users are willing to compromise the quality of outcome, by minimizing their investment in time and effort.

Regarding the low usage level of library source 
compared to the Web, previous studies provide some explanations. A study uncovered that only $1 \%$ of information seekers start with the library Web site (OCLC, 2005). Most users prefer the easier-to-use Web sources, even if it leads to information of poorer quality. One common complaint about the library's gateway was the complexity of search tools. It seems advisable to create a starting point on the library's gateway with an easy-to-use structure that can be customized for undergraduates as well as easy-to-use federated search engines that enable searching across different sources and databases. In fact, many libraries have attempted to implement federated search engines that facilitate searching across different resources and databases that the library has (Cox, 2007; Ruddock \& Hartley, 2010). Although such efforts have yielded some success, many agree that current federated search engines should be further empowered to enhance the user experience more positively. In the current systems, users still need to know how to formulate better search strategies for in-depth searches (Rogers, 2010). They also need to be informed of what federated search engines can do and how they work (Tang, Hsieh-Yee, \& Zhang, 2007). It seems logical to include more background information about federated search engines as well as instructions for good search strategies in information literacy education programs.

The findings of this study shed light on undergraduate students' source selection behavior. Apparently, students know what criteria to apply for the selection of quality sources. However, just as most other users, they are drawn to sources that are psychologically and physically accessible, requiring minimum effort from them. The study also revealed that the way in which undergraduates perceive and evaluate sources is often problematic and needs to be corrected.

To address the psychological accessibility issues, those who design and develop information systems might want to consider different ways to make information systems more user-friendly, easy to use, and interesting. For example, in order to maximize the "ease of use," library Websites could be designed more simple and easy to navigate while minimizing the number of clicks before finding the information searched. Faceted search options and tag clouds are among the popular features as they seem to make the library information systems more fun and easy to use (Nagy, 2011). Also, recent changes and updates in the interfaces and the record displays of OPACs toward the more website-like styles can be a good example of how libraries make efforts to craft the OPACs more easy to use to the undergraduates who are familiar with the displays of the websites. Additionally, many academic libraries have incorporated different levels of union catalogs in their federated search and Next-Generation Catalog features in order for the customers to search and access beyond the local catalog (Nagy, 2011). North Carolina State University Libraries (http://www. lib.ncsu.edu/) and The University of Chicago Library (http://www.lib.uchicago.edu/e/index.html) are some of the examples. To help students develop accurate perception and understanding of quality sources, those in charge of IL education would, first, need to help students become more exposed to various 
sources. Findings of the study revealed that many students were not familiar with quality sources, such as online databases. IL librarians should promote various quality sources available through their library and actively participate in IL training via different channels. Concurrently, by adopting some of the strengths of the Web, such as instant gratification and fun, librarians could design the IL program in a way to help users experience instant gratifications and playfulness from using quality sources. In an effort to enhance "interesting" characteristics, there has been some move to incorporate such features as Flickr and YouTube into the library portal. While it was a fresh idea at the outset and appeared to be attractive, users' actual receptions of the new features seem to be inconsequential. This experience suggests the task to make the library resources interesting very challenging. Yet, continuing efforts to incorporate such features and resources learned from user experience is a pivotal task for librarians and system designers, and thus such efforts should be continued and the outcome should be constantly monitored and evaluated (Tomeo, 2012).

IL programs embedded in actual classes can also be an effective approach in helping students experience benefits more directly and also in motivating students to learn to use quality sources more actively (Hamilton, 2008). When collaborating with faculty in designing course-related assignments, IL librarians might want to encourage faculty to require a variety of information sources other than the Web sources in students' academic assignments. Studies show the students' use of quality library sources was improved when instructors required the use of certain types of information sources other than Web sources. Each of these efforts would help undergraduate students become more familiar with quality information sources and gain more positive experience with the sources, which in turn would encourage them to return to the quality sources (Gerstberger \& Allen, 1968).

In sum, an important conclusion to be drawn from this study is that it is critical to make quality sources more accessible and easy to use through effective systems design. It is also crucial that IL librarians help users gain more experience in using them to increase the familiarity of sources. Increased familiarity with quality sources is important as it can make users more aware of them and enable them to better appreciate their values. These efforts might eventually help change users' perception of the quality of sources and lead to an increase in the use of quality sources.

\section{References}

Burton, V., \& Chadwick, S. (2000). Investigating the practices of student researchers: Patterns of use criteria for use of internet and library sources. Computers and Composition, 17(3), 309-328. 
Cox, C. (2007). Hitting the spot: Marketing federated searching tools to students and faculty. Serials Librarian, 53(3), 147-164.

Davis, P. (2003). Effect of the web on undergraduate citation behavior: Guiding student scholarship in a Networked age. Portal: Libraries and the Academy, 3(1), 41-51.

Gardner, S., \& Eng., S. (2005). What students want: Generation Y and the changing function of the academic library. Portal: Libraries and the Academy, 5(3), 405-420. Retrieved from http://muse.jhu.edu/journals/pla/

Generation Y. (August 30, 1993). Ad Age, p. 16.d.

Gerstberger, P., \& Allen, T. (1968). Criteria used by research and development engineers in the selection of an information source. Journal of Applied Psychology, 52(4), 272-279.

Hamilton, L. (2008). Embedding information literacy into the prehospital care curriculum. Journal of Emergency Primary Health Care, 6(1), Article 3. Retrieved from http://ro.ecu.edu.au/jephc/vol6/iss1/3/

Head, A. J., \& Eisenberg, M. B. (2009). Lessons learned: How college students seek information in the digital age. Project Information Literacy Progress Report, University of Washington's Information School. Retrieved from http://projectinfolit.org/pdfs/PIL_Fall2009_finalv_YR1_12_2009v2.pdf

Head, A. J., \& Eisenberg, M. B. (2010a). How today's college students use Wikipedia for course-related research. First Monday, 15(3). Retrieved from http://journals.uic.edu/ojs/index.php/fm/article/view/2830/2476

Head, A. J., \& Eisenberg, M. B. (2010b). Truth be told: How college students evaluate and use information in the digital age. Project Information Literacy Progress Report, University of Washington's Information School. Retrieved from http://projectinfolit.org/pdfs/PIL_Fall2010_Survey_FullReport1.pdf

Himmelfarb, S. (1993). The measurement of attitudes. In A.H. Eagly \& S. Chaiken (Eds.), Psychology of Attitudes, 23-88. Thomson/Wadsworth.

Holiday, W., \& Li, Q. (2004). Understanding the Millennials: Updating our knowledge about students. Reference Services Review, 32(2), 356-365.

Kim, K., \& Sin, S. (2007). Perception and selection of information sources by undergraduate students: Effects of avoidant style, confidence, and personal control in problem-solving. Journal of Academic Librarianship, 33(6), 655-665. http://dx.doi.org/10.1016/j.acalib.2007.09.012

Kuhlthau, C., Heinström, J., \& Todd, R. (2008). ISP revisited: Is the ISP-model still useful. Information Research, 13(4). paper 355. Retrieved from http://informationr.net/ir/13-4/paper355.html

Lee, H.-L. (2008). Information structures and undergraduate students. Journal of Academic Librarianship, 34(3), 211-219. http://dx.doi.org/10.1016/j.acalib.2008.03.004

Lee, J.-M. (2010). Seeking and using information sources by college students: Comparisons of information 
seeking in everyday life and during elections. Journal of the Korean Society for Library and Information Science, 36(1), 41-60. http://dx.doi.org/10.4275/KSLIS.2010.44.3.117

Lim, S. (2009). How and why do college students use Wikipedia? Journal of the American Society for Information science and Technology, 60(11), 2089-2202. http://dx.doi.org/10.1002/asi.21142

Mann, T. (1987). A guide to library research methods. New York: Oxford University Press.

Nagy, A. (2011). Analyzing the next-generation catalog. Library Technology Reports, 47(7), 5-28.

North Carolina State University (2013). Library's online catalog. Retrieved from http://www.lib.ncsu.edu/catalog/index.html

OCLC. (2005). Perceptions of libraries and information resources. Retrieved from http://www.oclc.org/reports/pdfs/Percept_all.pdf

Osgood, C. E. (1962). Studies of the generality of affective meaning systems. American Psychologist, 17, 10-28.

Osgood, C. E., Suci, G., \& Tannenbaum, P. (1957). The measurement of meaning. Urbana, IL: University of Illinois Press.

Rockman, I. F. (2004). Information literacy into the higher education curriculum: Practical models for transformation. San Francisco: Jossey-Bass.

Rogers, J. (2010). Some thoughts on federated search. Posted in attempting elegance. Retrieved from http://rogersurbanek.wordpress.com/2007/12/04/some-thoughts-on-federated-search/

Ruddock, B., \& Hartley, D. (2010). How UK academic libraries choose metasearch systems. Aslib Proceedings, 62(1), 85-105. http://dx.doi.org/10.1108/00012531011015226

Scoyoc, A., \& Cason, C. (2006). The electronic academic library: Undergraduate research behavior in a library without books. Portal: Libraries and the Academy, 6(1), 47-58. Retrieved from http://muse.jhu.edu/journals/pla/v006/6.1van_scoyoc.html

Tang, R., Hsieh-Yee, I., \& Zhang, S. (2007). User perceptions of metaLib combined search: An investigation of how users make sense of federated searching Internet. Reference Services Quarterly, 12(1\&2), 211-236.

Tomeo, M. L. (2012). Adding users to the Website design process. Public Services Quarterly, 8(4), 350-358. http://dx.doi.org/10.1080/15228959.2012.730414

Tversky, A., \& Fox, C. (2000). Weighing risk and uncertainty. In Choices, values and frames, New York: Russell Sage Foundation. (pp. 93-117).

University of Chicago (2013). Library's online catalog: http://lens.lib.uchicago.edu/

Valentine, B. (1993). Undergraduate research behavior: Using focus groups to generate theory. Journal of Academic Librarianship, 19(5), 300-304. 
Warwick, C., Rimmer, J., Blandford, A., Gow, J., \& Buchanan, G. (2009). Cognitive economy and satisficing in information seeking: A longitudinal study of undergraduate information behavior. Journal of the American Society for Information Science and Technology, 60(12), 2402-2415. http://dx.doi.org/10.1002/asi.21179

Yoon, J-O. (2004). Information seeking in context: content analysis of information search by college students. Journal of Korean Library and Information Science Society, 35(2), 199-218.

Young, N., \& Seggern, M. (2001). General information seeking in changing times. Reference \& User Services Quarterly, 41(2), 159-169.

Zipf, G. (1949). Human behavior and the principle of least effort. Cambridge, Mass: Addison-Wesley. 